\title{
Interferência da redução no volume de aplicação sobre o controle da mancha preta (Guignardia citricarpa Kiely) em frutos de laranja 'Valência'"
}

\author{
Demétrius de Araújoํㅜ, Carlos Gilberto Raetano², Hamilton Humberto Ramos ${ }^{3}$, Marcel Belatto Spósito 4 , Evandro \\ Pereira Prado 5
}

\begin{abstract}
${ }^{1} E_{n g}{ }^{0}$ Agrônomo, Mestre em Proteção de Plantas, Departamento de Proteção Vegetal, FCA/UNESP- Botucatu - SP. ${ }^{2}$ Eng. Agrônomo, Prof. Adjunto, Depto. Proteção Vegetal, FCA/UNESP, Botucatu - SP. ${ }^{3}$ Eng. Agrônomo, Pesquisador científico, Centro de Engenharia e Automação do Instituto Agronômico (CEA/IAC) Jundiaí-SP. ${ }^{4}$ Eng. Agrônomo, Pesquisador científico, Fundo de Defesa da Citricultura (FUNDECITRUS) Araraquara-SP. ${ }^{5}$ Eng ${ }^{\circ}$ Agrônomo, Doutor em Proteção de Plantas, Departamento de Proteção Vegetal, FCA/UNESP, Botucatu - SP. *Trabalho extraído da dissertação do primeiro autor, apresentada a Faculdade de Ciências Agronômicas - FCA/UNESP - para obtenção do título de mestre em Proteção de Plantas. Apoio financeiro: FAPESP e FUNDECITRUS.
\end{abstract}

Autor para correspondência: Carlos Gilberto Raetano (raetano @fca.unesp.br)

Data de chegada: 11/05/2012. Aceito para publicação em: 10/05/2013.

\section{RESUMO}

Araújo, D.; Raetano, C.G.; Ramos, H.H.; Spósito, M.B.; Prado, E.P. Interferência da redução no volume de aplicação sobre o controle da mancha preta (Guignardia citricarpa Kiely) em frutos de laranja 'Valência'. Summa Phytopathologica, v.39, n.3, p.172-179, 2013.

O controle químico do agente causal da mancha-preta-dos-citros (MPC) tem merecido destaque pelo excessivo número de pulverizações, elevando sobremaneira os custos de produção na citricultura. A busca por melhorias na eficiência das pulverizações e reduções na quantidade dos produtos fitossanitários já tem sido realizada, mas os resultados dessa prática ainda não são consistentes para que possa ser aplicado em escala comercial. Sendo assim, essa pesquisa objetivou avaliar a interferência da redução no volume de aplicação, sobre o controle químico da mancha preta em frutos cítricos. $\mathrm{O}$ experimento foi conduzido em pomar comercial com plantas de 16 anos de idade, da variedade Valência durante o ano agrícola 2007. Os tratamentos consistiram de três volumes de calda, 3,5;4,5 e $8,5 \mathrm{~L}$ planta $^{-1}$, aplicados por pulverizador de jato transportado Arbus 2000/ Export, com ramal especial de bicos, utilizando-se fungicidas e períodos recomendados para o controle da doença em um total de quatro pulverizações e mais um tratamento testemunha (sem pulverização).
As avaliações de incidência e severidade da doença ocorreram através de escala visual diagramática de notas em duas épocas (pré-colheita e colheita), em três alturas (baixo, médio e alto) da planta e mais três setores horizontais (entrada, frontal e saída) em dois lados da planta. Os frutos caídos foram contados quinzenalmente, em plantas previamente selecionadas, do início da maturação até a colheita com a quantificação da produção $\left(\mathrm{kg} \mathrm{planta}^{-1}\right)$. A incidência e severidade da doença foram menores quando as pulverizações foram realizadas com 8,5 $\mathrm{L} \mathrm{planta}^{-1}$ na primeira época de avaliação (pré-colheita), porém na colheita, não houve diferenças entre os mesmos parâmetros, quando pulverizados 4,5 ou $8,5 \mathrm{~L}_{\text {planta }}{ }^{-1}$. Nenhum tratamento reduziu a doença no setor alto da planta, em comparação a testemunha. Os setores da planta com os frutos mais expostos aos raios solares, lado direito e alto da planta, apresentaram maior incidência e severidade da doença. A redução no volume de 8,5 para $4,5 \mathrm{~L} \mathrm{planta}^{-1}$ pode ser praticada na citricultura sem prejuízo do nível de controle da MPC.

Palavras-chave adicionais: tecnologia de aplicação, citros, controle químico.

\section{ABSTRACT}

Araújo, D.; Raetano, C.G.; Ramos, H.H.; Spósito, M.B.; Prado, E.P. Interference of spray volume reduction in citrus black spot (Guignardia citricarpa Kiely) control in 'Valência' citrus fruits. Summa Phytopathologica, v.39, n.3, p.172-179, 2013.

The chemical control of the causal agent of citrus black spot (CBS) has been highlighted for the excessive required number of sprayings, considerably increasing citrus production costs. Improvements in the spray efficiency and reductions in the quantity of phytosanitary products have already been searched, but the results of that practice are not consistent yet for its use at commercial scale. Thus, the aim of the present study was to evaluate the interference of reduced spray volumes in black spot control in citrus fruits. The experiment was carried out in commercial citrus orchard with 16year-old plants of 'Valencia' variety, during 2007 agricultural season. Treatments consisted of three spray volumes: $3.5 ; 4.5$ and 8.5 liters.plant ${ }^{-1}$, applied with Arbus 2000/Export airblast sprayer with special manifold of hydraulic nozzles, using fungicides and periods recommended for the disease control, totaling four sprayings plus a control treatment (without spray). The disease incidence and severity were evaluated by visual diagrammatic scale of notes in two different periods (preharvest and harvest), at three plant heights (low, middle and top) and three horizontal sections (entrance, frontal and exit) in two sides of the plant. The fallen fruits were counted every fifteen days, for previously selected plants, from the beginning of maturation to harvest, and the production was quantified (kg.plant $\left.{ }^{-1}\right)$. The disease incidence and severity were significantly lower when sprayings were done with 8.5 liters.plant $^{-1}$ in the first evaluation period (pre-harvest), but in the harvest period there were not differences between the same parameters when 4.5 or 8.5 liters.plant $^{-1}$ were sprayed. None of those treatments reduced the disease on the top section of plants, compared to control. The plant sections with fruits more exposed to sun rays, top and right side of the plant, demonstrated higher disease incidence and severity. The volume reduction from 8.5 to 4.5 liters.plant ${ }^{-1}$ can be adopted for citrus orchards without damaging the CBS control level.

Additional keywords: application technology, citrus, chemical control. 
Apesar de ocupar posição de destaque no cenário agrícola mundial, a citricultura brasileira enfrenta vários problemas de natureza fitossanitária, dos quais a mancha-preta-dos-citros (MPC) vem trazendo sérios prejuízos ao setor e está disseminada em muitos municípios produtores de citros. A MPC é uma doença causada pelo fungo Guignardia citricarpa Kiely (fase anamórfica de Phyllosticta citricarpa McAlpine 1973), o qual é específico dos citros (3). Atualmente, a doença MPC está presente nos estados do Sul, Sudeste e Amazonas (18), bem como em vários países da África, Ásia, Oceania e América do Sul (20).

Em decorrência dos prejuízos potenciais, a MPC é classificada como quarentenária A1 para os Estados Unidos da América e países da União Européia, limitando significativamente a possibilidade de exportação de frutos in natura $(8 ; 20)$. A doença afeta tanto a aparência dos frutos através de lesões na casca, tornando-os inaceitáveis para o mercado de frutas frescas, mas podendo ser utilizado para processamento (21), como a queda dos frutos quando as condições são favoráveis ao desenvolvimento do patógeno (7), gerando grandes prejuízos à produção.

Com exceção da limeira ácida 'Tahiti' (C. latifolia Tanaka), da laranjeira 'Azeda' (C. aurantium L.) e seus híbridos, todas as variedades comerciais são suscetíveis, afetando todas as variedades de laranjasdoces (Citrus sinensis L. Osbeck), principalmente, aquelas de maturação tardia ('Valência' e 'Natal'); assim como os limões (C. limon (L.) Burn.), pomelos (C. paradisi Macfad.), tangerinas, como a Ponkan, Cravo e mexerica-do-rio, lima da pérsia (C. limettioides Tan.) e tangor (C. reticulata L. x C. sinensis), (20). A laranjeira 'Azeda' e seus híbridos, são resistentes ao fungo (10), já a lima-ácida 'Tahiti' $(C$. latifolia Tan.) é insensível ao patógeno, não exibindo sintomas da doença, embora o agente causal possa ser isolado do interior dos tecidos foliares e dos frutos (5).

Os frutos possuem um longo período de suscetibilidade ao fungo, que vai das fases iniciais de desenvolvimento (10), até pelo menos nas 24 semanas subsequentes (4). No geral, as principais tentativas de controle nesse período têm sido através de pulverizações fungicidas em períodos pré-estabelecidos (preventivo). O número de pulverizações para MPC e a severidade da doença têm aumentado nos pomares do estado de São Paulo, o que tem elevado excessivamente os custos de produção e, na maior parte das vezes, não tem proporcionado o controle desejado do patógeno.

Em alguns países tradicionais no cultivo de citros, a exemplo da África do Sul, fungicidas cúpricos são recomendados por meio de pulverizações foliares em volumes muito altos (10000 a 16000 L.ha $\left.{ }^{-1}\right)$ para o controle de MPC e mancha marrom de Alternária [Alternaria alternata (Fr.:Fr.) Keissl pv. citri] em intervalos de aplicações de 28 a 35 dias (19). Contrariamente, pesquisas australianas de Cunningham \& Harden, datadas de 1998 e 1999, consideram que o nível de retenção da pulverização para plantas cítricas adultas é de 2300 L.ha' ${ }^{-1}$ (19).

Pulverizações com volumes altos (4000-4500 L.ha-1) ainda são bastante frequentes nos pomares brasileiros, apesar de relatos em que o volume de pulverização não tem relação direta com a eficácia no controle (17). Ainda é pouco o número de trabalhos onde se estuda como e até quanto é possível reduzir o volume de pulverização de forma eficiente para o controle da MPC.

Resultados de trabalhos recentes visando o controle da MPC (2; $15 ; 16 ; 14)$ têm gerado dúvidas sobre quais são realmente os valores de redução nos volumes de pulverização que podem ser praticados a campo, sem alterar as concentrações recomendadas do fungicida na aplicação, de maneira a obter controle adequado dessa doença.

Assim, esse trabalho objetivou avaliar o efeito da redução do volume de aplicação (mantendo a mesma dosagem do ingrediente ativo por área no tratamento fitossanitário), sobre o controle da mancha preta em frutos cítricos, através de avaliações da incidência e severidade da doença, queda de frutos e produtividade da cultura.

\section{MATERIAL E MÉTODOS}

A partir do volume de calda convencionalmente utilizado em pomar comercial de citros $\left(8,5 \mathrm{~L} \mathrm{planta}^{-1}\right)$ foram selecionados os volumes de 3,5 e 4,5 $\mathrm{L}_{\text {planta }}{ }^{-1}$. Isso ocorreu com base nas averiguações preliminares de Ramos et al. $(15 ; 16)$ as quais partindo do volume de 6,0 até $4,0 \mathrm{~L}_{\text {planta }}{ }^{-1}$, não constataram diferenças significativas nas deposições e coberturas das pulverizações, trabalhando em pomar adulto da variedade cítrica Valência.

$\mathrm{O}$ experimento foi instalado no município de Mogi Guaçu/SP (22 ${ }^{\circ} 18^{\prime} 03$ 'S $-47^{\circ} 00^{\prime} 34^{\prime}$ 'O), durante a safra 2007 , em pomar comercial da variedade Valência com 16 anos de idade, plantado em espaçamento de 7,5 x 3,5 m, com histórico confirmado de ocorrência da MPC. O delineamento experimental foi inteiramente casualizado e, os tratamentos distribuídos no esquema $4 \times 2 \times 3 \times 3$, sendo o tratamento testemunha (sem pulverização) incluído no fator volume como zero, mais os três volumes: 3,$5 ; 4,5$ e $8,5 \mathrm{~L} \mathrm{planta}^{-1}$, combinados à pulverização realizada dos dois lados da planta: direito (maior insolação, sudoeste-SO) e esquerdo (nordeste-NE) e, avaliado em três setores horizontais na planta (entrada, frontal e saída), como também, em três setores verticais (baixo, médio e alto), com quatro repetições. Cada parcela foi constituída por sete linhas de plantio. Para as avaliações, foram utilizadas três linhas centrais de cada parcela, e as duas de cada extremidade mantidas como bordaduras tratadas.

As pulverizações foram realizadas conforme recomendação do Fundecitrus (9) para aplicação de produtos fitossanitários no controle da MPC, num total de quatro pulverizações. A calda de pulverização foi composta por um fungicida cúprico, na dosagem de $175 \mathrm{~g}$ de produto comercial (p.c.) $100 \mathrm{~L}^{-1}$ d'água $\left(840 \mathrm{~g} . \mathrm{kg}^{-1}\right.$ do ingrediente ativo oxicloreto de cobre) adicionado a um óleo mineral na concentração de $0,25 \% \mathrm{v} / \mathrm{v}$, para as duas primeiras pulverizações. Nas duas outras pulverizações utilizou-se o fungicida sistêmico, Derosal $500^{\circledR} \mathrm{SC}$ na dosagem de $100 \mathrm{~mL}$ de p.c. $100 \mathrm{~L}^{-1}$ d'água $(50 \%$ do ingrediente ativo carbendazim) e o fungicida Comet $^{\text {B }}$ na dosagem de $15 \mathrm{~mL}$ de p.c. 100 $\mathrm{L}^{-1}$ d'água (25\% do ingrediente ativo piraclostrobina), respectivamente para a terceira e quarta pulverizações, associados ao fungicida cúprico e o óleo nas mesmas dosagens descritas, conforme Tabela 1.

As pulverizações foram realizadas com um pulverizador de arrasto de jato transportado Arbus 2000/Export (Figura 1a), com ramal especial de bicos (Figura 1b), pulverizando em ambos os lados da linha de plantio.

O pulverizador foi tracionado por um trator Massey Ferguson ${ }^{\circledR}$ (modelo 275) trabalhando a $1800 \mathrm{rpm}$ (540 rpm na tomada de potência) na $2^{\mathrm{a}}$ marcha reduzida $\mathrm{A}$, que proporcionou uma velocidade do conjunto trator-pulverizador de $3,7 \mathrm{~km} \mathrm{~h}^{-1}$. Em alguns experimentos realizados na cultura dos citros, no Brasil, observou-se que a velocidade ideal para uma deposição e cobertura adequadas com pulverizadores de jato transportado se situa entre 2,0 e $5,0 \mathrm{~km} \mathrm{~h}^{-1}$ (13).

As pontas de pulverização foram reguladas para produzir um espectro de gotas com diâmetro mediano volumétrico (DMV) entre 150 e $200 \mu \mathrm{m}$, que segundo Ramos et al. (17) é uma faixa de DMVs que têm demonstrado boa eficiência de deposição das gotas em plantas cítricas. Com esses fatores pré-estabelecidos os modelos de ponta selecionados e suas respectivas pressões de trabalho, vazões $\left(\mathrm{L} \mathrm{min}^{-1}\right)$ e DMV para cada tratamento, são especificados na Tabela 2. 
Tabela 1. Período de realização das pulverizações, produtos e respectivas dosagens aplicadas em laranjeiras 'Valência' (Mogi Guaçu-SP).

\begin{tabular}{|c|c|c|c|}
\hline \multirow[t]{2}{*}{$\begin{array}{c}\text { Pulverização } \\
\text { (Data) }\end{array}$} & \multicolumn{2}{|c|}{$\begin{array}{l}\text { Fungicidas } \\
\text { Ingrediente ativo (produto comercial) }\end{array}$} & \multirow[t]{2}{*}{$\begin{array}{c}\text { Dosagem (g ou mL do p.c. } \\
100 \mathrm{~L}^{-1} \mathrm{~d}^{\text {‘água })}\end{array}$} \\
\hline & Contato & Sistêmico & \\
\hline Primeira (08 nov. 2006$)$ & oxicloreto de cobre (Cobox) & -- & $175 \mathrm{~g}$ \\
\hline Segunda (06 dez. 2006) & oxicloreto de cobre (Cobox) & -- & $175 \mathrm{~g}$ \\
\hline
\end{tabular}

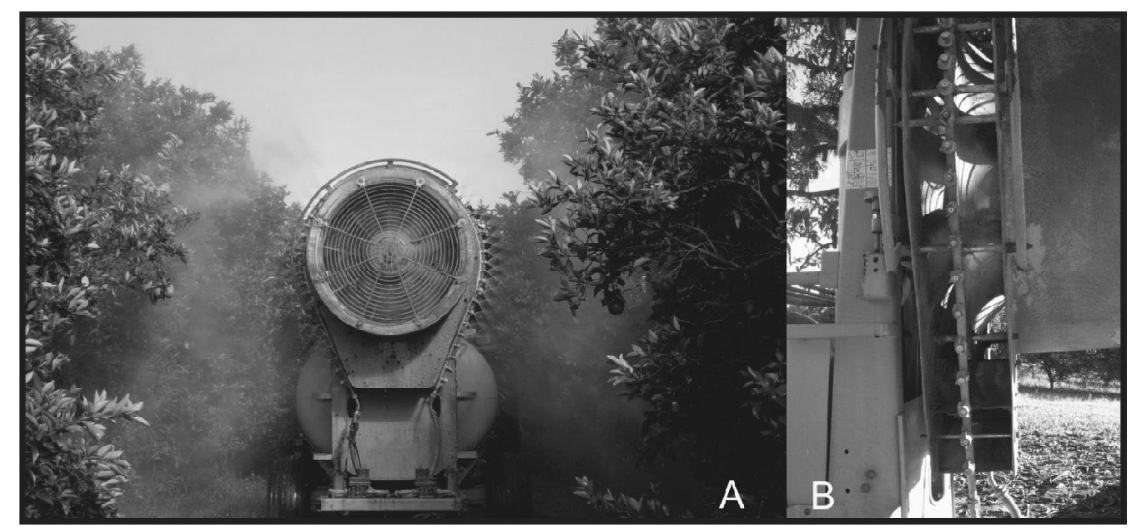

Figura 1. Pulverizador (Arbus 2000/Export - A) equipado com ramal especial de bicos (B) para as pulverizações visando o controle da MPC (Mogi Guaçu/ SP).

Tabela 2. Volume (L planta $\left.{ }^{-1}\right)$ e respectiva ponta de pulverização, pressão de trabalho, vazão e DMVs no tratamento fitossanitário de plantas cítricas (Mogi Guaçu-SP).

\begin{tabular}{ccccc}
\hline Volume $\left(\mathbf{L}\right.$ planta $\left.^{-1}\right)$ & Ponta/difusor & Pressão $(\mathbf{k P a})$ & ${\text { Vazão }\left(\mathbf{L} \mathbf{~ m i n}^{-1}\right)}^{\text {DMV }(\boldsymbol{\mu m})^{*}}$ \\
\hline 3,5 & $\mathrm{D} 3 / 25$ & 1587 & 1,62 & 134 \\
4,5 & $\mathrm{D} 3 / 45$ & 1587 & 2,08 & 154 \\
8,5 & $\mathrm{D} 6 / 25$ & 1587 & 3,94 & 163 \\
\hline
\end{tabular}

"Dados fornecidos pelo fabricante das pontas de pulverização empresa Spraying Systems Co ${ }^{\circledR}$.

Para avaliação do controle da doença foram utilizados os parâmetros incidência e severidade da doença (calculada pelo índice de doença - IDO). As avaliações da doença ocorreram em dois períodos da safra. O primeiro período foi chamado de pré-colheita, quando a maior parte dos frutos passou da coloração verde (casca) para amarela, pois segundo Kotzé (10) os sintomas podem aparecer quando o fruto está completamente desenvolvido com a casca ainda verde, no entanto, quanto mais maduro o fruto se torna, com a casca mudando de verde para amarelo ou laranja, melhor as chances de aparecerem os sintomas; assim, nesse período pretendia-se conhecer o efeito da doença sobre os frutos em uma fase inicial de maturação. E, a segunda, avaliação na época de colheita com a observação do ratio de colheita dos frutos (relação de sólidos solúveis por acidez) o qual deve ser utilizado para a tomada de decisão sobre o momento de colheita.

Quanto à divisão da planta em setores de avaliação, considerou-se primeiramente, a divisão em lado esquerdo (NE) e direito (maior insolação, SO), pois segundo Kotzé (10) os sintomas dessa doença pode se expressar em níveis mais severos, dentre outros motivos, em frutos que recebem maior incidência solar. Em seguida, para cada lado, a planta foi subdividida em três setores horizontais (entrada, meio e saída) e três setores verticais, baixo (do solo até $\pm 1,10 \mathrm{~m}$ de altura), médio (de 1,11 a 2,20 m) e alto (de 2,21 m até o topo). Desse total de
18 setores de avaliação foram estabelecidas notas visuais da doença em cada um, para 9 frutos ou, na ausência dessa quantidade, o número máximo de frutos presentes.

As lesões nos frutos foram avaliadas segundo a escala diagramática de notas adaptada daquela proposta por Spósito et al. (21) para melhor utilização em campo (Figura 2). Os avaliadores foram previamente treinados no campo quanto ao reconhecimento/distinção dos sintomas da MPC nos frutos e utilização da escala diagramática de forma a avaliarem plantas de todos os tratamentos, e o mesmo número de plantas para cada tratamento. A distribuição dos avaliadores em todos os tratamentos contribui para eliminação de uma possível avaliação tendenciosa, apesar de, a forma de elaboração da escala diagramática já proporcionar essa possibilidade de tendência na avaliação.

Para análise dos dados de severidade, calculou-se o índice de doença (IDO), por meio da fórmula:

$\mathrm{IDO}=(\%$ de área da casca lesionada $\mathrm{x}$ frequência $) \times 100 /\left(\mathrm{n}^{\circ}\right.$ total de frutos no setor avaliado $\mathrm{x} \%$ máxima de área lesionada)

Para realização do cálculo, cada nota da escala adaptada (Figura 2) apresenta uma porcentagem de área da casca lesionada correlacionada aos valores da escala diagramática original, conforme estabelecido na Tabela 3. Os dados de incidência foram calculados dividindo-se a soma do número de frutos com sintomas (notas com valores acima de zero) 


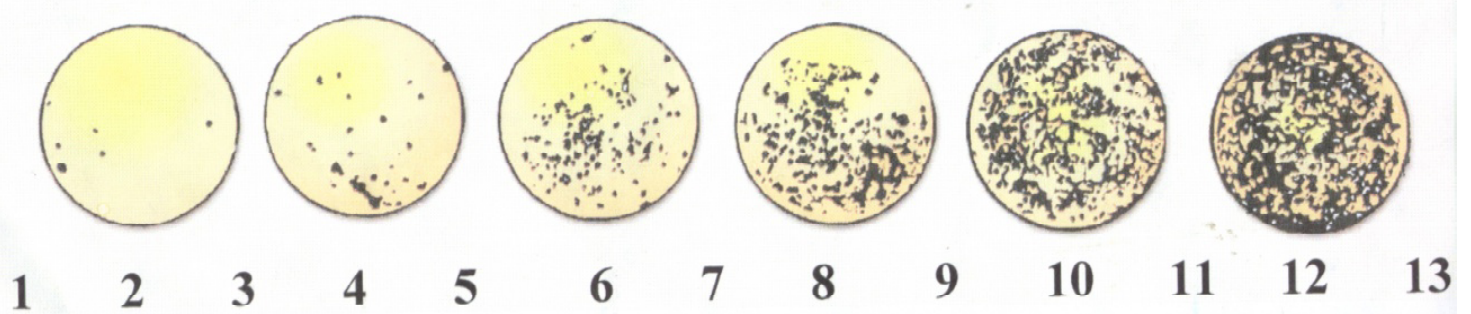

Figura 2. Escala diagramática adaptada de Spósito et al. (2004), para avaliação em campo da severidade da MPC (Guignardia citricarpa) em frutos cítricos (Citrus spp.).

Tabela 3. Notas da escala diagramática adaptada de Spósito et al. (2004) e abaixo os respectivos grau da escala, para cálculo da severidade da doença mancha preta (Mogi Guaçu-SP, 2007).

\begin{tabular}{|c|c|c|c|c|c|c|c|c|c|c|c|c|}
\hline \multicolumn{13}{|c|}{ Nota da escala adaptada } \\
\hline 1 & 2 & 3 & 4 & 5 & 6 & 7 & 8 & 9 & 10 & 11 & 12 & 13 \\
\hline \multicolumn{13}{|c|}{ Porcentagem de área da casca lesionada } \\
\hline 0,2 & 0,5 & 1,0 & 1,7 & 3,6 & 5,0 & 8,2 & 11,5 & 17,8 & 22,5 & 36,0 & 49,0 & 58,0 \\
\hline
\end{tabular}

Obs: Valores em negrito correspondentes à escala de severidade da mancha preta proposta por Spósito et al. (2004).

pelo número de frutos avaliados no setor, vezes cem, o que forneceu a porcentagem de frutos que expressou a doença.

Devido a relatos de pesquisas afirmarem existência de alta correlação entre níveis de severidade da doença e porcentual de queda dos frutos (7), que em condições favoráveis à doença essa queda pode provocar até $50 \%$ de redução na produção da planta (22), também foram realizadas avaliações quinzenais da queda de frutos, do início do amadurecimento até a colheita.

Nas avaliações de queda dos frutos, primeiramente, foram selecionadas e marcadas três plantas por parcela, as mesmas utilizadas para avaliação da incidência/severidade da doença e submetidas a uma limpeza inicial sob a copa, retirando-se todos os frutos caídos. Após esta atividade, quinzenalmente os frutos foram rastelados e contados, totalizando sete avaliações. Na sétima avaliação, após a limpeza, as árvores marcadas tiveram todos os frutos remanescentes colhidos $\mathrm{e}$ contados, de maneira a quantificar a produção da área experimental e verificar a interferência da doença, e dos tratamentos realizados, na produção final das plantas.

\section{RESULTADOS E DISCUSSÃO}

\section{Incidência e severidade da doença sobre os frutos.}

Na pré-colheita (30/08/2007), verificou-se que houve influência significativa do lado direito da planta (exposto para a localização sudoeste da área de plantio) na incidência de lesões da MPC sobre frutos, com valores médios significativamente maiores aos observados no lado esquerdo da planta (Tabela 4). Apesar de não confirmar esse fato na segunda avaliação (colheita em 29/10/2007) desse parâmetro, verifica-se que, na maioria das vezes, a incidência da doença MPC apresenta correlação positiva com a maior exposição dos frutos aos raios solares. Caixeta et al. (6) estudando a caracterização de isolados de G. citricarpa de diferentes regiões citrícolas do Brasil e da África do Sul observaram maior destaque referente à formação de estruturas reprodutivas (conídios) nas temperaturas de 20 e $25{ }^{\circ} \mathrm{C}$ e fotoperíodo de 12 horas. Já Andrade et al. (1) constataram menores níveis de severidade da MPC em frutos de laranjeiras 'Natal' e 'Valência' de pomares implantados no alinhamento $\mathrm{N}-\mathrm{S}$, enquanto no alinhamento NE-SO foram constatados maiores níveis de severidade.

Tabela 4. Incidência de frutos de laranjeira 'Valência' (\%) com lesões de mancha preta em dois lados da planta, direito (maior exposição ao sol) e esquerdo, na primeira época de avaliação. (Mogi Guaçu -SP, 2007).

\begin{tabular}{ccc}
\hline Lado & Incidência (\%) \\
\hline Direito (SO) & $55,05 \mathrm{a}$ \\
Esquerdo (NE) & $43,80 \mathrm{~b}$ \\
\hline DMS (5\%) $=4,91$ & Média geral $=49,43$ & C.V. $(\%)=42,79$ \\
\hline
\end{tabular}

A análise do desdobramento dos valores médios de incidência da doença para a interação entre os fatores volume e setor vertical na primeira época (pré-colheita) permitiu inferir que, para cada um dos setores verticais entre plantas, o aumento do volume, partindo do zero (testemunha) apresentou relação inversa à incidência da doença. Porém, a redução da doença foi significativa somente com o maior volume aplicado, 8,5 L planta ${ }^{1}$ (Tabela 5). Dentro de cada volume avaliado, o setor alto da planta foi o que apresentou as maiores incidências de frutos com lesões e o setor baixo, as menores. No setor médio da planta a incidência de lesões foi estatisticamente igual àquela do setor alto da planta, para o tratamento testemunha e, para os demais volumes de pulverização, no setor médio foram verificados valores médios intermediários de incidência, não diferindo dos valores nos demais setores da planta.

Na segunda época de avaliação (colheita), considerando a mesma interação de fatores anteriormente descrita, verificouse que os valores médios de incidência aumentaram em relação à primeira época, especialmente para o tratamento testemunha 
Tabela 5. Desdobramento dos valores médios da incidência de frutos de laranjeira 'Valência', (\%) com lesões da MPC em três setores verticais na planta, para diferentes volumes de pulverização, na primeira época de avaliação (Mogi Guaçu - SP).

\begin{tabular}{|c|c|c|c|c|}
\hline \multirow{3}{*}{$\begin{array}{c}\text { Volume } \\
\text { (L planta-1) }\end{array}$} & \multicolumn{4}{|c|}{ Incidência (\%) } \\
\hline & \multicolumn{4}{|c|}{ Setor vertical } \\
\hline & Baixo & Médio & & Alto \\
\hline 0,0 & $45,57 \mathrm{a}^{1} \mathrm{~B}$ & $60,09 \mathrm{a}$ & A & 70,39 a $A$ \\
\hline 3,5 & 50,19 a $\mathrm{B}$ & 58,18 a & $\mathrm{AB}$ & 69,19 a $\mathrm{A}$ \\
\hline 4,5 & 39,31 a $\mathrm{B}$ & 45,95 a & $\mathrm{AB}$ & 60,19 a $\mathrm{A}$ \\
\hline 8,5 & $20,76 \mathrm{~b} \quad \mathrm{~B}$ & $29,78 \mathrm{~b}$ & $\mathrm{AB}$ & $43,52 \mathrm{~b} \quad \mathrm{~A}$ \\
\hline \multicolumn{2}{|c|}{ Média Geral $=49,43$} & \multicolumn{3}{|c|}{ DMS $(5 \%)$ para colunas $=15,80$} \\
\hline \multicolumn{2}{|c|}{$\mathrm{CV}(\%)=42,79$} & \multicolumn{3}{|c|}{ DMS $(5 \%)$ para linhas $=14,40$} \\
\hline
\end{tabular}

${ }^{1}$ Médias seguidas por letras iguais nas colunas (minúsculas) e nas linhas (maiúsculas) não diferem pelo teste de Tukey ao nível de $5 \%$ probabilidade

no qual atingiu valores de aproximadamente $100 \%$ em todos os setores verticais de avaliação. Valores médios significativamente maiores de incidência da doença foram obtidos em plantas não tratadas nos setores médio e baixo da planta (Tabela 6). No entanto, na parte alta da planta não houve diferença na incidência da doença, entre plantas tratadas e não tratadas. Assim, denota-se que, a soma dos fatores: maior exposição à chuva durante a época das pulverizações contribuindo para a remoção do fungicida sobre os frutos; a tendência de menores deposições do produto com esse tipo de pulverizador; a maior exposição dos frutos aos raios solares no setor alto da planta; além do maior tempo de permanência do fruto na planta para as variedades de ciclo tardio ('Valência'), inviabiliza o controle dessa doença no setor alto da planta em regiões epidêmicas do patógeno, independente do volume de pulverização.

Ainda pode-se constatar que, dentro dos volumes aplicados de 3,5; 4,5 e 8,5 $\mathrm{L} \mathrm{planta}^{-1}$, a incidência da doença sobre os frutos apresentou correlação positiva com a altura da planta, de forma significativa entre os três setores. Na aplicação de $8,5 \mathrm{~L} \mathrm{planta}^{-1}$ os melhores resultados no controle da doença foi no setor baixo das plantas, porém não diferindo estatisticamente daquele obtido com 4,5 $\mathrm{L}_{\text {planta }}{ }^{-1}$. Isso viabiliza a redução do volume aplicado para 4,5 L

Tabela 6. Desdobramento dos valores médios da incidência de frutos de laranjeira 'Valência', (\%) com lesões da MPC em três setores verticais na planta, para diferentes volumes de pulverização, na segunda época de avaliação (Mogi Guaçu-SP).

\begin{tabular}{|c|c|c|c|c|}
\hline \multirow{3}{*}{$\begin{array}{c}\text { Volume } \\
\left.\text { (L planta }{ }^{-1}\right)\end{array}$} & \multicolumn{4}{|c|}{ Incidência (\%) } \\
\hline & \multicolumn{4}{|c|}{ Setor vertical } \\
\hline & Baixo & Médio & & Alto \\
\hline 0,0 & $99,61 \mathrm{a}^{1} \mathrm{~A}$ & 99,49 a & A & 99,83 a $A$ \\
\hline 3,5 & $74,04 \mathrm{~b} \quad \mathrm{C}$ & $84,65 \mathrm{~b}$ & $\mathrm{~B}$ & 98,14 a $\mathrm{A}$ \\
\hline 4,5 & 66,09 bc $\mathrm{C}$ & $81,93 \mathrm{~b}$ & $\mathrm{~B}$ & 96,05 a $A$ \\
\hline 8,5 & 58,59 c $\mathrm{C}$ & $80,48 \mathrm{~b}$ & $\mathrm{~B}$ & 97,22 a $A$ \\
\hline \multicolumn{2}{|c|}{ Média Geral $=86,34$} & \multicolumn{3}{|c|}{$\overline{\operatorname{DMS}(5 \%) \text { para colunas }=9,9460}$} \\
\hline \multicolumn{2}{|c|}{ C.V. $(\%)=15,42$} & \multicolumn{3}{|c|}{ DMS $(5 \%)$ para linhas $=9,0628$} \\
\hline
\end{tabular}

${ }^{1}$ Médias seguidas por letras iguais nas colunas (minúsculas) e nas linhas (maiúsculas) não diferem pelo teste de Tukey ao nível de 5\% probabilidade planta $^{-1}$, já que não foi inferior ao maior volume pulverizado em nenhum dos parâmetros avaliados na colheita.

Seguindo a mesma tendência dos registros anteriores, onde o lado da planta influenciou significativamente sobre os parâmetros avaliados, verifica-se que a severidade da doença foi maior no lado direito da planta na primeira época de avaliação - pré-colheita (Tabela 7), confirmando a correlação positiva entre severidade e exposição dos frutos aos raios solares e, na maior parte das vezes, corroborando com

Tabela 7. Severidade, expresso pelo índice de doença da MPC sobre frutos de laranjeira 'Valência', segundo o lado da planta considerado, na primeira época de avaliação. (Mogi Guaçu - SP).

\begin{tabular}{ccc}
\hline Lado & Severidade $^{1}$ \\
\hline Direito & $0,94^{2} \mathrm{a}$ \\
Esquerdo & $0,69 \mathrm{~b}$ & \\
\hline DMS $(5 \%)=0,11$ & Média geral $=0,82$ & C.V. $(\%)=58,72$ \\
\hline
\end{tabular}

as informações de Kotzé (10).

Em relação ao volume de pulverização e setor vertical da planta nota-se que, na época da pré-colheita ocorre maior diferenciação entre tratamentos (Tabela 8), com redução progressiva dos valores de severidade das plantas não tratadas para o maior volume pulverizado $\left(8,5 \mathrm{~L}_{\text {planta }}{ }^{-1}\right)$. O volume de 4,5 $\mathrm{L}_{\text {planta }}{ }^{-1}$ não diferiu do volume de 3,5 $\mathrm{L} \mathrm{planta}^{-1}$, porém a severidade foi significativamente menor com 4,5 $\mathrm{L}_{\text {planta }}{ }^{-1}$ em relação às plantas não tratadas. Na época da colheita (Tabela 8), a testemunha expressa valor de severidade da doença significativamente maior em relação aos demais tratamentos e com valor absoluto superior. Já entre os volumes aplicados não foram observados diferenças significativas.

Os setores vertical alto e médio da planta foram os locais com maior severidade da doença na pré-colheita. Já na colheita, a severidade apresentou relação direta com a altura da planta (Tabela 9), evidenciando maior ineficácia de controle no setor alto da planta em pomares epidêmicos, com esse tipo de aplicação, como já foi discutido anteriormente.

De modo geral, não houve efeito significativo no desdobramento da interação entre volume de pulverização e setores horizontais de amostragem na planta (entrada, frontal e saída) sobre a severidade e

Tabela 8. Severidade, expressa pelo índice de doença, da MPC sobre frutos de laranjeira 'Valência', para diferentes volumes de pulverização, em duas épocas de avaliação. (Mogi Guaçu-SP).

\begin{tabular}{ccc}
\hline Volume & \multicolumn{2}{c}{ Severidade $^{1}$} \\
\cline { 2 - 3 } (L planta $\left.^{-1}\right)$ & Pré-Colheita $^{(2)}$ & Colheita $^{\text {Col }}$ \\
\hline 0,0 & $1,03 \mathrm{a}$ & $6,56 \mathrm{a}$ \\
3,5 & $0,90 \mathrm{ab}$ & $2,68 \mathrm{~b}$ \\
4,5 & $0,78 \mathrm{~b}$ & $1,96 \mathrm{~b}$ \\
8,5 & $0,55 \mathrm{c}$ & $1,96 \mathrm{~b}$ \\
\hline & Média: 0,82 & Média: 3,29 \\
& CV(\%): 58,72 & CV(\%): 59,98 \\
& DMS(5\%): 0,16 & DMS(5\%): 0,67 \\
\hline
\end{tabular}

${ }^{1}$ Médias seguidas por letras iguais na coluna não diferem pelo teste de Tukey ao nível de $5 \%$ de probabilidade.

${ }^{2}$ Dados transformados por raiz (x) 
Tabela 9. Severidade (expressa pelo índice de doença) da MPC sobre frutos de laranjeira 'Valência', segundo o setor vertical da planta, em duas épocas de avaliação. (Mogi Guaçu - SP).

\begin{tabular}{|c|c|c|}
\hline \multirow[t]{2}{*}{ Setor Vertical } & \multicolumn{2}{|c|}{ Severidade $^{1}$} \\
\hline & Pré-Colheita (2) & Colheita \\
\hline Alto & $0,95 \mathrm{a}$ & $4,93 \mathrm{a}$ \\
\hline Médio & $0,84 \mathrm{a}$ & $2,95 \mathrm{~b}$ \\
\hline \multirow[t]{4}{*}{ Baixo } & $0,66 \mathrm{~b}$ & $1,99 \mathrm{c}$ \\
\hline & Média: 0,82 & Média: 3,29 \\
\hline & $\mathrm{CV}(\%): 58,72$ & CV(\%): 59,98 \\
\hline & $\operatorname{DMS}(5 \%): 0,16$ & $\operatorname{DMS}(5 \%): 0,67$ \\
\hline
\end{tabular}

${ }^{1}$ Médias seguidas por letras iguais na coluna não diferem pelo teste de Tukey ao nível de $5 \%$ de probabilidade.

${ }^{2}$ Dados transformados para raiz (x)

incidência da doença mancha preta sobre frutos cítricos. Isso demonstra que, nessa safra, a ocorrência de inóculo do fungo provavelmente foi maior na época de suscetibilidade dos frutos e, portanto, não sendo suficiente para detectar diferença dos níveis de infestação e severidade da MPC entre os setores horizontais de amostragem na planta.

\section{Queda de frutos e produção}

A queda dos frutos foi crescente com a época de avaliação, porém sendo menor nas três primeiras avaliações, intermediária nas duas avaliações seguintes ( 14 e 28 de setembro) e significativamente maiores na sexta ( 15 de outubro) e sétima ( 29 de outubro) avaliações (Tabela 10). O progresso na maturação dos frutos e da severidade da doença contribuiu para a elevação do número de frutos caídos com o passar das avaliações, principalmente nas duas últimas.

Os dados climáticos confirmaram que o número de dias com temperaturas acima de $21^{\circ} \mathrm{C}$ foi consideravelmente crescente de agosto até outubro (Tabela 11) e, dessa forma, pode ter favorecido o patógeno a deixar sua fase de dormência, confirmando as afirmações de Laranjeira et al. (12), consequentemente aumentando a incidência e severidade da doença, bem como a queda dos frutos, ao longo desse período.

Apesar de não haver diferença estatística entre tratamentos, quanto à porcentagem acumulada da queda de frutos ao longo das avaliações, verifica-se a partir dos 58 dias após o início das contagens que as

Tabela 10. Interferência da época de avaliação sobre o número médio (n $=12$ plantas) de queda dos frutos de laranjeira 'Valência' em pomar com alta ocorrência da doença MPC. (Mogi/Guaçu-SP).

\begin{tabular}{cc}
\hline Época de avaliação & Média $\left(\mathbf{n}^{\mathbf{0}}\right.$ de frutos/época) ${ }^{\mathbf{1}}$ \\
\hline Sétima $(29 / 10 / 2007)$ & $10,16 \mathrm{a}^{(2)}$ \\
Sexta $(15 / 10 / 2007)$ & $9,86 \mathrm{a}$ \\
Quarta $(14 / 09 / 2007)$ & $8,18 \mathrm{~b}$ \\
Quinta $(28 / 09 / 2007)$ & $7,60 \mathrm{~b}$ \\
Terceira $(30 / 08 / 2007)$ & $4,65 \mathrm{c}$ \\
Primeira $(31 / 07 / 2007)$ & $4,08 \mathrm{c}$ \\
Segunda $(15 / 08 / 2007)$ & $3,63 \mathrm{c}$ \\
\hline CV $(\%)=17,36$ & $\operatorname{DMS}(5 \%)=1,28$ \\
\hline
\end{tabular}

${ }^{1}$ Dados transformados para raiz de $\mathrm{x}$.

${ }^{2}$ Médias seguidas por letras iguais na coluna não diferem pelo teste de Tukey ao nível de $5 \%$ de probabilidade.
Tabela 11. Número de dias/mês com temperaturas médias acima de $21^{\circ} \mathrm{C}$, adequadas para expressão dos sintomas da MPC, durante as avaliações na área experimental (Mogi Guaçu/SP, 2007).

\begin{tabular}{ccc} 
Número de dias por mês com temperaturas médias acima de $\mathbf{2 1}^{\circ} \mathbf{C}$ \\
\hline Agosto & Setembro & Outubro \\
0 & 11 & 21 \\
\hline
\end{tabular}

diferenças entre testemunha (maior porcentagem de queda) e os outros tratamentos foram crescentes (Figura 3), com diferenças de 15 e 18\% em relação ao tratamento com a segunda maior queda acumulada (volume de 3,5 $\mathrm{L} \mathrm{planta}^{-1}$ ), respectivamente nas duas últimas avaliações.

Em relação à produção $\left(\mathrm{kg}_{\mathrm{p}} \operatorname{lanta}^{-1}\right)$, pode se verificar que no tratamento testemunha foi significativamente inferior àquelas obtidas nos tratamentos que receberam pulverizações fungicidas, os quais não diferiram entre si (Tabela 12).

$\mathrm{O}$ tratamento que apresentou a maior porcentagem acumulada de queda de frutos ao final das avaliações (testemunha) foi também o que resultou em menor produção estimada para o início das avaliações (soma de todos os frutos caídos mais frutos colhidos no final), com valor de 166,53 kg planta-1 (4,1 caixas planta $\left.{ }^{-1}\right)$, e os demais tratamentos produziram em média 4,$9 ; 5,2$ e 5,4 caixas planta ${ }^{-1}$, respectivamente para os volumes de 3,$5 ; 4,5$ e 8,5 L $_{\text {planta }}{ }^{-1}$.

Com a observação dessa baixa produção estimada, verifica-se que, no tratamento testemunha pode ter ocorrido considerável queda precoce de frutos, antes de iniciarem as avaliações de queda no experimento. Considerando a hipótese de Kotzé (11), que, às vezes, mesmo com poucas lesões nos frutos pode ocorrer a sua queda, leva a suspeitar do efeito de infecções ocorridas no pedúnculo dos frutos

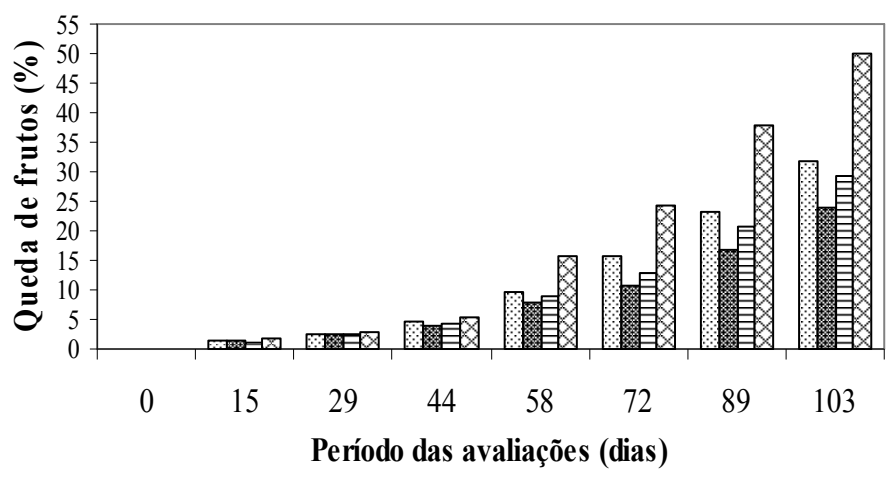

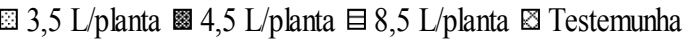

Figura 3. Porcentagem acumulada de queda de frutos para diferentes volumes de pulverização e épocas de avaliação da MPC (Mogi Guaçu-SP).

Tabela 12. Média das produções de plantas de laranjeira 'Valência' entre os tratamentos com e sem pulverização para o controle da doença MPC (Mogi Guaçu-SP).

\begin{tabular}{cc}
\hline Tratamentos & Produção média $\left(\mathbf{k g}\right.$ planta $\left.^{-1}\right)$ \\
\hline $8,5 \mathrm{~L} \mathrm{planta}^{-1}$ & $161,31 \mathrm{a}^{(1)}$ \\
$4,5 \mathrm{~L} \mathrm{planta}^{-1}$ & $154,38 \mathrm{a}$ \\
$3,5 \mathrm{~L} \mathrm{planta}^{-1}$ & $135,63 \mathrm{a}$ \\
Testemunha (sem pulverização) & $83,38 \mathrm{~b}$ \\
\hline & CV $(\%)=26,85$ \\
& DMS $(5 \%)=39,13$ \\
\hline
\end{tabular}

${ }^{1}$ Médias seguidas por letras iguais na coluna não diferem pelo teste de Tukey ao nível de $5 \%$ de probabilidade. 
cítricos. Assim, isso pode ter ocorrido com os frutos ainda verdes.

No geral, pode-se evidenciar que, o controle químico não proporcionou eficiência desejada na redução da MPC sobre frutos. No entanto, pelos dados finais da produção do pomar $\left(\mathrm{kg}\right.$ planta $\left.{ }^{-1}\right)$, pode-se afirmar que volumes de pulverizações menores que $8,5 \mathrm{~L}$ planta $^{-1}$ podem ser utilizados, reduzindo-se os custos e aumentando significativamente a capacidade operacional dos equipamentos por ocasião do tratamento fitossanitário na citricultura. Estes resultados corroboram com aqueles obtidos por Ramos et al. $(16 ; 14)$, os quais evidenciaram a possibilidade de redução do volume de pulverização na citricultura. Portanto, essas evidências suportam a hipótese de que fatores como precipitação pluviométrica e pouca uniformidade no florescimento são bastante relevantes na incidência e severidade da MPC.

A redução no volume de pulverização 8,5 para $4,5 \mathrm{~L}_{\text {planta }}{ }^{-1}$ pode ser praticada na citricultura sem prejuízo do nível de controle da mancha-preta-do-citrus MPC na época de colheita dos frutos.

$\mathrm{O}$ maior tempo de permanência do fruto na planta, aliado às condições climáticas favoráveis à doença, são agravantes importantes no aumento da incidência e severidade da doença, bem como na queda dos frutos.

Todos os tratamentos foram ineficientes na redução da incidência e severidade da doença no terço superior das plantas, evidenciando a necessidade de melhoria na técnica de aplicação para esse setor da planta.

A maior exposição de partes da planta aos raios solares lado da planta exposto para a localização geográfica sudoeste e setor alto - favorece a maior expressão da doença MPC.

\section{AGRADECIMENTOS}

À Fundação de Amparo à Pesquisa do Estado de São Paulo (FAPESP) e ao Fundo de Defesa da Citricultura (FUNDECITRUS) pelo apoio financeiro concedido e à empresa Fischer SA pelo interesse e incentivo à pesquisa e suporte técnico.

\section{REFERÊNCIAS BIBLIOGRÁFICAS}

1. Andrade, A.G.; Pimenta, A.A.; Goes, A. Influência do alinhamento de plantio na severidade da mancha-preta-doscitros, produção e qualidade do suco. Revista Brasileira de Fruticultura, Jaboticabal, v.31, n.4, p.1033-1041, 2009.

2. Araújo, D.; Ramos, H.H.; Spósito, M.B.; Yanai, K.; Pompolo, L.F.; Galvão, I.V. Interação entre dois ramais de pulverização, três arranjos de pontas de pulverização e duas pressões de trabalho para o controle da mancha preta sobre frutos de laranjeira 'Valência' - deposição da pulverização. In: Simpósio Internacional de Tecnologia de Aplicação, 4., 2008, Ribeirão Preto. Anais... Campinas: Instituto Agronômico, 2008. 1 CDROM.

3. Baayen, R.P.; Bonants, P.J.M.; Verkley, G.; Carroll, G.C.; Van der Aa, H.A.; De Weerdt, M.; Van Brouwershaven, I.R.; Schutte, G.C.; Maccheroni, W. J.R.; Glienke De Blanco, C.; Azevedo, J.L. Nonpathogenic isolates of the citrus black spot fungus, Guignardia citricarpa, identified as a cosmopolitan endophyte of woody plants, G. mangiferae (Phyllosticta capitalensis). Phytopathology, St. Paul, v.92, p.464-477, 2002.

4. Baldassari, R.B.; Reis, R.F.; Goes, A. de. Susceptibility of fruits of the 'Valencia' and 'Natal' sweet orange varieties to Guignardia citricarpa and the influence of the coexistence of healthy and symptomatic fruits. Fitopatologia Brasileira,
Brasília, v. 31, n.4, p.337-341, 2006

5. Baldassari, R.B.; Wickert, E.; Goes, A. de. Pathogenicity, colony morphology and diversity of isolates of Guignardia citricarpa and G. mangiferae isolated from Citrus spp. European Journal of Plant Pathology, Wageningen, v. 120, n. 1, p.103- 110,2008

6. Caixeta, M.P.; Corazza, M.J.; Oliveira, R.R.; Zanutto, C.A.; Nunes, W.M.C.; Vida, J.B. Caracterização morfofisiológica e identificação molecular de isolados de Guignardia citricarpa, agente patogênico da mancha preta dos citros. Acta Scientiarum Agronomy, Maringá, v. 30, supl., p. 625-630, 2008.

7. Fagan, C.; Goes, A. de. Efeito da severidade da mancha preta dos frutos cítricos causada por Guignardia citricarpa na queda prematura de frutos de laranja 'Natal'. Fitopatologia Brasileira, Brasília, v.24, supl., p.282, 1999.

8. Fischer, I.H.; Toffano, L.; Lourenço, S.A.; Spósito, M.B.; Amorim, L. Incidência de mancha preta em frutos cítricos em diferentes etapas de beneficiamento em packinghouses e na Ceagesp SP. Tropical Plant Pathology, Brasília, v.33, n.4, p.326-330, 2008 .

9. Fundecitrus. Calendário de pulverizações. In: Manual de pinta preta. Araraquara, 2005. p.11

10. Kotzé, J.M. Epidemiology and control of citrus black spot in South Africa. Plant Disease, St. Paul, v.65, p.945-950, 1981.

11. Kotzé, J.M. History and epidemiology of citrus black spot in South Africa. Proceedings of the International Society Citriculture, Sun City, p.1296-1299, 1996.

12. Laranjeira, F.F.; Amorin, L.; Filho, A.B.; Aguilar-Vildoso, C.I.; Filho, H.D.C. Fungos, procariotos e doenças abióticas. In: Junior, D. de M.; Negri, J.D.; Pio, R.M.; Junior, J.P. Citros. Campinas: Instituto Agronômico/ Fundag, 2005. p. 511-558.

13. Raetano, C.G. Condições operacionais de turboatomizadores na distribuição e deposição da pulverização em citros. 1996. $92 \mathrm{f}$. Tese (Doutorado em Agronomia) - Escola Superior de Agricultura "Luiz de Queiroz", Universidade de São Paulo, Piracicaba, 1996.

14. Ramos, H.H.; Araújo, D.; Spósito, M.B.; Yanai, K.; Rocha, E.F.R. da; Galvão, I. V. Interação entre dois ramais de pulverização, três arranjos de pontas de pulverização e duas pressões de trabalho no controle da mancha preta sobre frutos de laranjeira 'Valência'. In: Simpósio Internacional de Tecnologia de Aplicação, 4., 2008, Ribeirão Preto. Anais... Campinas: Instituto Agronômico, 2008c. 1 CD-ROM.

14. Ramos, H.H.; Araújo, D.; Spósito, M.B.; Yanai, K.; Rocha, E.F.R. da; Galvão, I. V. Interação entre dois ramais de pulverização, três arranjos de pontas de pulverização e duas pressões de trabalho no controle da mancha preta sobre frutos de laranjeira 'Valência'. In: Simpósio Internacional de Tecnologia de Aplicação, 4., 2008, Ribeirão Preto. Anais... Campinas: Instituto Agronômico, 2008c. 1 CD-ROM.

16. Ramos, H.H.; Araújo, D.; Yanai, K.; Spósito, M.B.; Galvão, I.V.; Rocha, E.F.R. da; Pompolo, L.F. Interação entre seis volumes de aplicação e três diâmetros medianos volumétricos de gotas sobre a deposição da calda de pulverização em diferentes tamanhos de frutos de laranjeira 'Valência'. In: Simpósio Internacional de Tecnologia de Aplicação, 4., 2008, Ribeirão Preto. Anais... Campinas: Instituto Agronômico, 2008a. 1 CD-ROM.

17. Ramos, H.H.; Yanai, K.; Araújo, D.; da Rocha, D.S.R.; Spósito, M.B.; Bassanezi, R.B. Estado da arte na tecnologia de aplicação em frutíferas - volume de aplicação e diâmetro de gotas. Summa Phytopathologica, Botucatu, v.33, supl., p.110-112, 2007.

18. Feichtenberger, E.; Baldassari, R.B.; Spósito, M.B.; Belasque Junior, J. Doenças dos citros. In: Kimati, H.; Amorim, L.; Rezende, J.A.M.; Bergamin Filho, A.; Camargo, L.E.A. (Eds.). Manual de fitopatologia. São Paulo: Ceres, 2005. v.2, p.239269 .

19. Schutte, G.C.; Kotzé, C.; Van ZYL, J. G.; Fourie, P. H. Assessment of retention and persistence of copper fungicides 
on orange fruit and leaves using fluorometry and copper residue analyses. Crop Protection, Surrey, v.42, p.1-9, 2012.

20. Sousa, P.F.C; Góes, A. Reação de laranjeiras-doces quanto à resistência a Guignardia citricarpa. Revista Brasileira de Fruticultura, Jaboticabal, v.32, n.3, p.718-725, 2010.

21. Spósito, M.B.; Amorin, L.; Júnior, J.B.; Bassanezi, R.B.; Aquino, R. de. Elaboração e validação de escala diagramática para avaliação da severidade da mancha preta em frutos cítricos. Fitopatologia Brasileira, Brasília, v.29, n.1 (jan-fev), p.81$85,2004$.

22. Spósito, M. B.; Amorim, L.; Ribeiro Jr, P. J.; Bassanezi, R. B.; Krainski, E. T. Spatial pattern of trees affected by black spot in citrus groves in Brazil. Plant Disease, St. Paul, v.91, n.1, p. $36-40,2007$. 